\title{
INVESTIGACIÓN/RESEARCH
}

\section{UN NUEVO LENGUAJE PARA LOS MEDIOS PERIODÍSTICOS DIGITALES. LA NECESIDAD DE ADAPTARSE AL CONTINUUM INFORMATIVO. PRIMERAS EXPERIENCIAS EN ESPAÑA}

Manuel de Ramón Carrión ${ }^{\mathbf{1}}$ : Universidad Complutense de Madrid. España manuelalberto.ramon@ccinf.ucm.es

\section{RESUMEN}

Los medios de comunicación escrita están ensayando en el mundo digital sistemas para narrar las noticias en directo, al menos las más importantes, en abierta competencia con los medios audiovisuales. La búsqueda de la instantaneidad les impulsa a modificar las técnicas de redacción incorporando nuevos sistemas como la emisión de titulares de una o dos líneas que permiten simultanear el mensaje con el desarrollo de la noticia y constituyen una expresión más del relato fragmentado. La escritura no puede competir en velocidad con la emisión de voz, pero estos titulares al menos suponen un paliativo. En este artículo se exponen los resultados de un estudio de campo realizado sobre las informaciones en forma de titulares lanzadas por EIPais.com la tarde en que fue elegido el Papa Francisco. El resultado es la constatación de que el conjunto de los 243 mensajes emitidos durante las siete horas y 14 minutos que duró la "transmisión" constituyeron una "crónica digital de titulares" que podría convertirse en un nuevo género periodístico. Sin embargo, se necesitarán estudios específicos para comprobar si el lector es capaz de obtener una idea global de la noticia al seguir ese relato fragmentado.

PALABRAS CLAVE: Prensa - Titulares - Twitter - Mensajes - Instantaneidad Continuum informativo.

\footnotetext{
${ }^{1}$ Autor correspondiente:

Manuel de Ramón Carrión: Facultad de Ciencias de la Información de la Universidad Complutense de Madrid. España

Correo: manuelalberto.ramon@ccinf.ucm.es
} 


\title{
A NEW LANGUAGE FOR DIGITAL MEDIA. THE NEED TO ADAPT TO THE SO CALLED CONTINUOUS INFORMATION. FIRST EXPERIENCES IN SPAIN
}

\begin{abstract}
Written media is testing new ways of telling live news in the digital world that would mean new competition for audiovisual media. The need for instantaneity brings them to invent new systems to inform people, for example by the use of headlines which consist only of one or two written lines. This represents the possibility of sending news in the exact moment as the news is happening and is an expression of the fragmented story telling. Even though written media cannot compete with the high speed of voice, these short headlines can actually become an alternative to audiovisual media. This article shows the results of a survey carried out by EIPais.com, the day the Pope Francisco was elected. In it, 243 messages broadcasted during seven hours and 14 minutes, the actual duration of the broadcast, became a "digital headlines chronicle". This meant a total innovation in the spanish Journalism. However, it would be necessary to carry out studies to find out if readers are in fact able to obtain a global idea of news only by reading a fragmented story of it.
\end{abstract}

KEYWORDS: Press media - Headlines - Twitter - Messages - Instantaneity Continuous information.

\section{INTRODUCCIÓN}

La llegada de Internet ha provocado un cambio total en el panorama de la comunicación, obligando a los llamados medios convencionales a adaptarse al nuevo "ecosistema". Los medios periodísticos escritos han experimentado una nueva evolución. En la faceta digital están buscando nuevas formas lingüísticas que para aprovechar de manera eficiente las posibilidades de instantaneidad que brinda la Red.

Vivimos un tiempo de cambios que algunos estudiosos como el profesor Lozano Bartolozzi denominan "Postperiodismo". El "ecosistema informativo" ha cambiado radicalmente: "Toda la sociedad es hoy un ecosistema informativo. Consecuencia de ello es la emergencia de una nueva etapa en la evolución de la prensa que me gusta calificar como postperiodismo" (Lozano Bartolozzi, 2006, p. 211).

Los medios digitales, tanto los "nativos" que han sido creados exclusivamente para difundirse en Internet y no se han publicado nunca en el soporte de papel ${ }^{2}$, como las ediciones digitales de los diarios convencionales, han experimentado una clara

\footnotetext{
2 Público.es se ha convertido en un diario digital moderno tras una fugaz trayectoria por el mundo tradicional del papel. Lo más significativo es que Público (2007-2012), que tal vez haya sido el último periódico de papel fundado en España, se ha convertido en un vivero de nuevos medios para la Red. Varios grupos de sus antiguos redactores han constituido cooperativas y han fundado periódicos en Internet como EIDiario.es e infoLibre.
} 
evolución, desde una primera etapa basada en los códigos lingüísticos propios del estilo de redacción de los periódicos de papel, hasta llegar a la convicción de que la Red constituye un nuevo medio que exige su propio lenguaje.

A pesar de que todavía estaríamos ante una fase de ensayos, aquella primera etapa de mera traslación de los textos del papel al digital ha quedado prácticamente superada. Sin embargo, ha surgido un nuevo reto para los medios escritos en Internet: la instantaneidad. Los digitales necesitan crear un nuevo lenguaje escrito que les permita relatar los grandes hechos informativos, no sólo en directo, sino de forma instantánea.

El lenguaje escrito, tanto en su elaboración como en su lectura, no puede competir en velocidad con el lenguaje oral. Los medios audiovisuales, sobre todo la Radio, superan a los diarios convencionales en inmediatez a la hora de relatar una noticia en directo. El Periodismo escrito tuvo que refugiarse desde los años 50 del siglo XX o incluso antes, en el análisis y la elaboración reposada de las informaciones para competir con la Radio y la Televisión. Tras la revolución digital, ya no le basta con cambiar de soporte para sobrevivir. En contra de lo que pudo pensarse en los años 90, ya no es suficiente con cambiar de soporte y pasar del papel a la pantalla electrónica. Ahora es imprescindible buscar la instantaneidad de la comunicación para competir con los medios audiovisuales, que a su vez utilizan habitualmente las oportunidades que brinda la Red publicando textos en sus respectivas páginas Web.

Por si no fuera suficiente competencia la de la Radio y la TV, la prensa digital tiene que afrontar también la que surge desde las Redes Sociales 2.0, en especial Twitter, que se ha constituido en una especie de "red de alerta temprana" con un renacimiento de los antiguos "flash" periodísticos. Sirven de aviso para usuarios y periodistas.

Los tuits emitidos desde las cuentas de los medios convencionales constituyen también un reclamo para que los usuarios no profesionales se informen en ese medio. Un tuit que anuncie la "fumata blanca" en el Vaticano es un reclamo para que los seguidores se conecten con ese medio. En este tipo de acontecimientos "abiertos", con noticias "vivas", siempre resultará más atractivo informarse a través de quien pueda contarlas en directo. En esas ocasiones, si el medio escrito persiste en la utilización de los géneros periodísticos propios del papel irá a remolque y perderá mucha audiencia, que quizá vuelva (o tal vez no) cuando considere que ya hay una información más reposada y analítica.

$\mathrm{Si}$ los medios digitales escritos quieren competir en instantaneidad con los audiovisuales, van a necesitar un nuevo lenguaje que aunque se exprese en un código alfabético les permita narrar en directo las noticias abiertas. Todo ello a costa de renunciar al análisis de las causas y las consecuencias. Lo contrario, la tentación de narrar la noticia de forma oral o con imágenes, les conducirá a convertirse en medios audiovisuales renunciando a su verdadera herramienta: el lenguaje escrito.

Hasta ahora se han ensayado dos métodos principales. El primero es la difusión de mensajes cortos, similares a los de Twitter aunque sin el corsé de los 140 caracteres. 
Constituyen versiones más o menos sofisticadas de esta red social, pero de acceso restringido a los profesionales de cada medio con objeto de adaptarlas a los diarios/continuos digitales de Internet.

En ElPaís.com este sistema se denomina "Última Hora" (también en el formato para PDA y teléfonos móviles), con anterioridad fue bautizado como "Eskup"3, pero ahora este título parece reservado a una red social del periódico donde escriben redactores y lectores.

El segundo método, más reciente pero todavía poco desarrollado, consiste en el lanzamiento de titulares descriptivos de una situación o de un acontecimiento aunque sin relato o crónica que los acompañe. En EIPaís.com se ha utilizado sólo en grandes acontecimientos, como la elección del cardenal argentino Julio María Bergoglio como nuevo Papa.

Este nuevo, llamémosle "género" periodístico, no ha recibido ningún nombre concreto, por lo que para entendernos en este artículo, y de forma provisional, podríamos denominarlo como "crónica digital de titulares" o simplemente "crónica de titulares".

\section{METODOLOGÍA}

Este trabajo tiene un horizonte más amplio que el que aquí se expone. En realidad, debe considerarse como el primer paso para una investigación que permita demostrar que se está produciendo o no una evolución del lenguaje escrito en los medios digitales en la dirección que se expresa. Esto es, en los casos en que se precisa realizar un relato en directo de los grandes hechos noticiosos, los medios digitales abandonan progresivamente los antiguos esquemas del lenguaje del Periodismo de papel para crear uno propio. Sin embargo, una investigación como la que se sugiere precisa de más tiempo para ver si se consolida ese nuevo género de la "crónica de titulares".

La metodología utilizada para este trabajo tiene dos vertientes principales. Por un lado, la observación directa de las técnicas lingüísticas utilizadas por un importante medio "escrito digital". Para ello, se ha realizado un trabajo de campo y un seguimiento de los todavía no muy numerosos testimonios encontrados por ahora de la "crónica de titulares". Se ha tratado sobre todo de analizar y evaluar el nuevo "lenguaje" periodístico-escrito, que se está creando para incorporar la prensa digital a la inmediatez. También se ha mantenido una entrevista con Ricardo de Querol, responsable de la edición digital de EIPaís.com y, naturalmente, se ha consultado la bibliografía ya existente.

\section{ANÁLISIS Y DISCUSIÓN.}

El artículo plantea como hipótesis que la posibilidad (y sobre todo la necesidad) de

\footnotetext{
${ }^{3}$ Adaptación a la fonética castellana del término periodístico inglés scoop, que equivale a "exclusiva" o "pisotón".
} 
competir en instantaneidad con los medios audiovisuales en el terreno de Internet está impulsando a los medios escritos a explorar esas nuevas técnicas lingüísticas. $Y$ hablamos de "necesidad", porque si los medios escritos no se lanzan a competir en instantaneidad/simultaneidad con los audiovisuales, están condenados a ser engullidos por los nuevos actores multimediáticos. Como se ha dicho, los medios audiovisuales no tienen reparos a la hora de incorporar textos a sus respectivas Webs.

Por tanto, se trata de rastrear y verificar los pasos que está dando el periodismo digital español para adaptar el lenguaje escrito del Periodismo impreso al lenguaje digital escrito para narrar las noticias en directo. Como se verá más adelante, está desapareciendo el concepto periodístico de ciclos temporales y se está adoptando el del "continuum". La información continua que, al ritmo de la actualidad permanente, difumina también el tradicional concepto de "ediciones". Lluis Bassets, periodista de "El País", resume el cambio experimentado por la prensa escrita en su adaptación a Internet: "No tendremos periódicos, al ritmo temporal marcado por la jornada diaria, sino continuos: los nombres que los han caracterizado, diario, periódico, semanario, mensual, dejarán de tener sentido para las nuevas marcas, totalmente desvinculadas de un ritmo temporal" (Lluis Bassets, 2013, p. 108).

No hace tanto que la mayoría de los intentos por crear un lenguaje periodístico adaptado a Internet habían tratado de cambiar sobre todo los formatos, pero sin variar "el lenguaje ni la redacción" y sin tener en cuenta los recursos de que dispone el periodista en la Red, según la afirmación que recoge Fátima Fernández del libro de Eduard Noci "La Escritura Digital" (Fernández, 2010, p. 71).

\subsection{Un nuevo lenguaje para un nuevo medio. La situación actual y su evolución en los últimos años}

Ante la actual encrucijada, el Periodismo escrito necesita dotarse de nuevas herramientas expresivas. El análisis, la interpretación y la reflexión, armas tradicionales de la prensa para competir con los medios audiovisuales, resultaron útiles durante todo el siglo XX. Los cambios en el "ecosistema mediático" han permitido a los tres medios convencionales usar Internet como nuevo soporte, que a su vez se ha convertido rápidamente en un medio con personalidad propia. Como ya se ha dicho, la Prensa puede jugar ahora en el propio terreno de los audiovisuales, pero debe competir en inmediatez. Si renunciase al texto, su seña de identidad lingüística, podría convertirse en una simple, y mala, imitación de los otros medios. El Periodismo escrito no puede limitarse a adoptar miméticamente el lenguaje audiovisual para insertarlo en una página Web.

Se ha impuesto una evolución de ese lenguaje periodístico escrito para adaptarlo a las necesidades de la simultaneidad informativa sin renunciar a la comunicación mediante la "letra impresa"4.

\footnotetext{
${ }^{4}$ Realmente, en Internet, la denominación de "Prensa" o "Periodismo impreso" se debe más a la tradición que a una realidad tecnológica, porque estas publicaciones ya no salen de ninguna rotativa.
} 


\section{2. ¿Los periódicos deberán llamarse "continuos"?}

Hemos visto como Lluis Bassets afirma taxativamente que los "periódicos" ya no son tales. Ya no funcionan por ciclos temporales porque la producción digital se asemeja más a un río que a la publicación de la prensa de papel, que se corresponde con los ciclos impuestos por la industria tipográfica. (Bassets, 2013, p. 108).

Para el profesor Ramón Salaverría: "Desde que, a finales del siglo pasado, los medios de internet descubrieron el tirón informativo de las noticias de última hora, adoptaron un modelo editorial de cierre continuo" (Salaverría, 2012, blog) ${ }^{5}$. Las empresas consideraron que con Internet el periodismo escrito podía salvar la brecha de varias horas de diferencia que existe desde que se cierra el diario en la redacción hasta que llega al quiosco.

Asimismo, cualquier noticia importante que surja tras el cierre de la edición resultará difícil que sea recogida. Y lo mismo ocurre con cualquier error en la elaboración del periódico una vez que las rotativas están funcionando. Gracias a Internet, el periodismo escrito puede dar noticias de última hora y mejor que aquellas páginas llamadas Última hora, Al cierre, etc.

No obstante, Salaverría desmitifica la idea del "caudal continuo" de informaciones al afirmar que "los medios digitales están aprendiendo a acompasar su oferta informativa a los hábitos temporales del público", porque hay que concentrar las noticias en los momentos en que son más demandadas (Salaverría, 2012).

\subsection{De la crónica periodística a la información fragmentada}

El género de la crónica es uno de los más antiguos del Periodismo. Muchos autores consideran el "Anábasis" de Jenofonte como una crónica de carácter histórico y los historiadores romanos escribían crónicas en las que, con las debidas cautelas, algunos estudiosos quieren ver un primer germen del Periodismo.

En esta segunda década del siglo XXI, parece que ya ha pasado el tiempo de las grandes crónicas interpretativas cuando se informa de una noticia en directo. El análisis y la reflexión vendrán después. Una vez que la noticia esté "cerrada", los periodistas podrán recuperar el estilo del periodismo escrito, aunque sin olvidar que el diario digital no admite un simple "volcado" de los contenidos del papel y también teniendo en cuenta las ventajas y los condicionantes propios del mundo digital como la hipertextualidad, los desfases horarios y geográficos y la "infidelidad" del lector.

Pastora Moreno Espinosa considera que Internet se ha convertido en un nuevo espacio comunicacional: "Hay un giro destacado en el modo de presentar, representar y distribuir la información, rompiendo las barreras de espacio y tiempo que amenazan a la prensa bajo el soporte de papel". (Moreno Espinosa, 2010, p. 132)

\footnotetext{
${ }^{5}$ En negrita en el original.
} 
Para lograr la simultaneidad informativa se precisa un nuevo lenguaje escrito que se adapte a esa instantaneidad que poseen los medios audiovisuales. Un lenguaje, pero también un nuevo género periodístico que debe incluirse entre los géneros informativos.

Entre los primeros ensayos que se han hecho analizaremos el caso de la elección del nuevo Papa Francisco, narrada en directo por EIPaís.com a base de titulares. El principal defecto de estos titulares es que el mensaje resulta demasiado rígido e inconexo. Estaría más próximo al "relato fragmentado" (Martínez Arias y De Ramón, 2013) que a la narración de un medio audiovisual.

La lentitud que impone todavía la escritura con teclado obliga a crear un relato discontinuo y casi telegráfico. Cuando progrese la tecnología y se puedan dictar las informaciones sin errores, ese discurso simultáneo podría acercarse más a un lenguaje natural con componentes narrativos, si bien el redactor deberá esforzarse siempre por facilitar la comprensibilidad.

\subsection{El "flash" en el "continuum". Vieja técnica del periodismo escrito y nueva herramienta para los desafíos presentes.}

Antes de entrar de lleno en el contenido que sugiere el título de este epígrafe, habría que detenerse a recordar qué se entiende por "información fragmentada". Se trata de relacionar la información en Twitter con la capacidad del lector para reconstruir mentalmente una historia. Esto es, las posibilidades que tiene el receptor de Twitter para "reescribir" una crónica de la que sólo ha recibido datos de una noticia de forma fragmentaria.

José Cerezo asegura que la "información fragmentada" consiste en "retazos de realidad de unos pocos bits, noticias que en segundos se difunden en el mundo interconectado para hacerse un hueco durante también apenas unos segundos en el magma de información en el que vivimos" (Cerezo 2008).

Un nuevo modelo de saber ha llegado con Internet y las Redes Sociales. Este cambio ha obligado a los profesionales del Periodismo a adaptar su estilo y sus técnicas de redacción a los requerimientos de estos nuevos canales. Surge así un "relato fragmentado" que podría definirse como "la comunicación seriada y constante de una noticia que se produce a lo largo de un periodo de tiempo concreto" (Martínez Arias y De Ramón, 2013). Hay numerosos ejemplos de información basada en el relato fragmentado. Además de los grandes acontecimientos (elección papal), hay otros cotidianos como una rueda de prensa o un partido de fútbol. Sin olvidar otros nada deseables como un atentado terrorista o una gran catástrofe.

En estos casos, Twitter, Facebook y otras redes, ofrecen un primer flash de urgencia y amplían la información con nuevos datos según se van conociendo. El flash es la forma más eficaz de mensaje urgente que se ha encontrado hasta ahora para afrontar las exigencias que imponen las características físicas de Twitter, donde hay que expresarse con solo 140 caracteres tipográficos. 
Esta característica "física" (los 140 caracteres) supone un corsé para cualquier género periodístico clásico. Los tuits constituirían así la versión cibermediática de los tradicionales flash periodísticos, pero también cabe considerarlos como titulares que logran un primer impacto informativo. Si se quiere ampliar con más datos, será necesario enviar un segundo tuit, un tercero y así sucesivamente. Se podría relatar una noticia relativamente extensa, pero en pequeños fragmentos. (Martínez Arias y de Ramón, 2013).

Este sería el primer paso para adaptar el lenguaje periodístico escrito a la información en directo. El siguiente, y más difícil, es narrar el acontecimiento de forma simultánea y en abierta competencia con los medios audiovisuales. Aquí entraría la que hemos llamado "la crónica de titulares". La duda, como ya se ha dicho, es si el lector está capacitado para reconstruir esa crónica en su cerebro y obtener un conocimiento aproximado de la realidad global.

\section{5. ¿Podría el lector obtener el conocimiento global de una noticia con una crónica de titulares?}

En este epígrafe tomaremos como referencia el estudio "Periodismo Ciudadano y Periodismo de Fuentes en las Redes Sociales. La Red Twitter como expresión del Relato Informativo Fragmentado", realizado por Santiago Martínez Arias y Manuel de Ramón para Cybermedia II, el último proyecto de investigación que dirigió don Mariano Cebrián.

El citado trabajo analizó en 2012 los tuits lanzados por los medios de comunicación (Periodismo Profesional), los clubes de fútbol (Periodismo de Fuentes) y los aficionados (Periodismo Ciudadano) durante las finales de la Liga Europa y de la Copa del Rey.

El objetivo era verificar si una persona que no estuviera viendo el partido era capaz de sacar una idea global del encuentro leyendo sólo los tuits de tres emisores de información (Profesional, Fuentes y Ciudadanos). En definitiva, se intentó averiguar si ese periodismo fragmentado podía equivaler a una crónica digital elaborada con distintos mensajes escritos en 140 caracteres y lanzados de forma aleatoria en cada partido.

El resultado fue la constatación de que tanto el Periodismo Profesional (Diario As), como el Periodismo de Fuentes (cuentas oficiales de los equipos participantes), sólo ofrecían una somera descripción del hecho noticioso (los partidos).

Durante la final de la Copa del Rey, el diario As emitió sólo diez tuits, un número escaso que ofrecía un relato excesivamente fragmentado incluso para seguir con atención la narración del encuentro, porque como media envió un tuit cada nueve minutos. En aquellos dos partidos el periódico utilizó Twitter como elemento secundario de su actividad informativa. Es posible que sus responsables ni siquiera se hubieran planteado la posibilidad de elaborar una crónica fragmentada global. 
Naturalmente, el relato que ofrecieron los clubes de fútbol en ambos partidos resultó sesgado por la pasión y el lógico partidismo. La situación fue aún peor en el Periodismo Ciudadano, encarnado por los hinchas. La mayoría tuiteó antes y después del partido, pero salvo casos excepcionales, apenas apareció durante el periodo de juego. La falta de mensajes pudo deberse a factores de tipo emocional (quien se dedique a tuitear mensajes desde el estadio puede perderse los goles) o bien de tipo técnico por la saturación del ciberespacio en las grandes aglomeraciones.

Es preciso reconocer que estos ejemplos resultan todavía escasos para sacar conclusiones generales sobre las posibilidades de que un lector recree mentalmente una crónica con mensajes cortos.

\subsection{Las experiencias actuales}

El 13 de marzo de 2013 se comunicó por primera vez en la historia la elección de un Papa a través de las redes sociales. Twitter y Facebook principalmente compitieron con los medios convencionales para contar la noticia. Asimismo, como ya se ha dicho, los medios escritos también relataron la noticia en directo.

La edición digital de EIPaís.com utilizó un doble sistema. Por un lado, emitió en streaming, pero por otro, también utilizó el texto escrito para narrar lo que sucedía, pero no empleó la forma de una crónica convencional, sino con titulares de un máximo de tres líneas que daban la sensación de instantaneidad característica de los medios audiovisuales.

\subsubsection{Observación directa de un caso concreto}

Habemus Papam (EIPaís.com, 13 de marzo de 2013)

Para realizar este trabajo hemos acotado una franja entre las 16,12 y las 23,26 horas del 13 de marzo de 2013. El primer mensaje apareció en ElPaís.com poco antes de las cuatro y cuarto $(16,12)$ para informar del comienzo de la quinta reunión del Conclave. La publicación regular de mensajes concluyó a las 23,26.

A lo largo de siete horas y 14 minutos, ElPaís.com colgó 243 mensajes con una cadencia de algo más de medio mensaje por minuto. Este cálculo corresponde a la media de toda la tarde-noche, pero el volumen de mensajes se incrementó considerablemente en los momentos clave hasta alcanzar los máximos picos de tráfico (1,24 por minuto).

Hubo tres momentos fundamentales: la aparición de la fumata blanca, el anuncio del nombre del nuevo pontífice y la salida del Papa Francisco al balcón del Vaticano. El primero de estos picos (fumata blanca) abarca desde las 19,06 en que aparece el primer mensaje: "Elección papal. Hay papa. FUMATA BLANCA EN EL VATICANO:" (sic) hasta las siete y media de la tarde. 
Durante ese lapso de tiempo (24 minutos), aparecen 27 mensajes al ritmo de 1,12 por minuto. El segundo periodo ("anuncio oficial") va desde las 19,30 hasta las 20,15 horas. En total, 45 minutos en los que ElPaís.com cuelga 56 mensajes con una media de 1,24 por minuto. Finalmente, el tercer pico ("el Papa en el balcón") abarca desde las 20,18 horas hasta las 21,06 (48') con 42 mensajes (0,87 por minuto). Es decir, durante 117 minutos apareció más de un mensaje por minuto (125).

La extensión osciló entre las tres palabras: "Continúa saliendo humo" $(19,16)$, hasta los mensajes de tres líneas. Conviene destacar que ninguno de los 243 mensajes superó las tres líneas de extensión. La mayoría constaban de sólo dos líneas: 94 en total, equivalentes al $38,68 \%$.

Los de tres líneas sumaron 70 mensajes $(28,8 \%)$, mientras que los 51 mensajes de una línea representaron casi el 21 por ciento. Se han desagregado los que tenían una extensión de hasta diez palabras (25 mensajes que equivalieron al 10,3\%) y los de más de diez palabras en una sola línea (26 en total, 10,7\%).

La distribución tampoco es aquí homogénea. Los mensajes de una sola línea se concentran sobre todo en los tres picos informativos. En esos 117 minutos se colgó el $72,5 \%$ de los mensajes cortos (37). Semejante concentración se explicaría por la urgencia para relatar lo que estaba ocurriendo, sin que el redactor pudiera detenerse a escribir un texto ni siquiera de tres líneas.

De ahí que debamos insistir en este trabajo académico en la idea de que el ansia de instantaneidad de los medios escritos les está impulsando a crear un nuevo género periodístico, la "crónica digital de titulares" como aplicación directa y profesional del llamado relato fragmentado.

En este sentido, es destacable que la mayoría de las oraciones de los mensajes vayan en tiempo Presente, lo que da al relato mayor sensación de instantaneidad. He aquí algunos ejemplos: "Elección papal. La plaza está llena de paraguas. Cae una fina lluvia sobre Roma" (16,52). "Se abren las puertas del ventanal en la logia central del balcón de la basílica de San Pedro" (20,12). "Es Jorge Mario BERGOGLIO, el arzobispo de Buenos Aires" $(20,13)$. Y como último ejemplo, entre muchos: "El Papa Francisco I, vestido de blanco, sale al balcón a saludar sin la estola, solo con la sotana blanca. Imagen de austeridad" $(20,22)^{6}$.

Los textos de tres líneas, se concentran en la primera parte de la tarde. Entre las 16,12 y las 18,59 se publican 23 mensajes de tres líneas. Esta mayor presencia podría deberse a la falta de noticias reales. Muchos de esos mensajes podrían encuadrarse en la "crónica de ambiente". Sólo describen detalles o aportan datos de background, tal como hacen los locutores de medios audiovisuales en retransmisiones en directo a la espera de la verdadera noticia (por ejemplo, la llegada de autoridades a un acto).

Los redactores de ElPaís.com contaban "noticias" como que "una gaviota se había

\footnotetext{
${ }^{6}$ Las negritas y las palabras en mayúscula aparecen en el original periodístico.
} 
posado en la chimenea del Vaticano y algunos la habían confundido con el Espíritu Santo" hasta los métodos de votación: "Elección papal. Cada cardenal tiene que escribir el nombre en un papel y después, uno a uno, con el papel en alto, se levantan y van hasta el centro de la capilla, donde depositan el voto en una urna después de rezar una pequeña jaculatoria asegurando que votan en conciencia" $(17,23)^{7}$.

A medida que transcurría el tiempo, el deseo de que se produjese por fin la fumata empujaba a hacer conjeturas como ésta: "Elección papal. La gaviota se ha ido de la chimenea. Quizá haya oído ruidos abajo, o haya empezado a sentir como se calienta" $(18,26)$. Además de los mensajes breves, se cuelgan enlaces, fotografías y vídeos para integrarlos en la crónica.

En la primera de las tablas estadísticas podemos observar la distribución de los mensajes en los periodos de la noticia. También hay datos sobre la frecuencia de los mensajes, extensión media, enlaces y el material gráfico que contenían.

Se ha constatado que al menos intervinieron diez autores en esta crónica digital, tanto redactores con su firma clásica (David Alandete) o con su cuenta de Twitter (@franciscoperegil) como varias agencias de noticias a las que se cita (Efe y Europa Press). Parece lógico que estas "crónicas de titulares" no pueden tener un solo autor debido a su extensión, la importancia de la noticia y la duración del hecho noticioso.

Tabla 1. Cuantificación de los mensajes

\begin{tabular}{|l|l|l|l|l|l|l|l|}
\hline $\begin{array}{l}\text { FASES DEL } \\
\text { RELATO }\end{array}$ & $\begin{array}{l}\text { 1.- Previo } \\
\text { a la } \\
\text { Fumata } \\
\text { Blanca }\end{array}$ & $\begin{array}{l}\text { 2.- } \\
\text { Fumata } \\
\text { Blanca }\end{array}$ & $\begin{array}{l}\text { 3.- } \\
\text { Anuncio } \\
\text { elección } \\
\text { Papa } \\
\text { Francisco }\end{array}$ & $\begin{array}{l}\text { 4.- Datos } \\
\text { biográficos } \\
\text { del nuevo } \\
\text { Papa }\end{array}$ & $\begin{array}{l}\text { 5.- } \\
\text { Primera } \\
\text { aparición } \\
\text { Papa } \\
\text { Francisco }\end{array}$ & $\begin{array}{l}\text { 6.- } \\
\text { Reacciones } \\
\text { y más } \\
\text { detalles }\end{array}$ & $\begin{array}{l}\text { 7.- Revista } \\
\text { Prensa } \\
\text { Extranjera }\end{array}$ \\
\hline $\begin{array}{l}\text { Duración de } \\
\text { la fase }\end{array}$ & $\begin{array}{l}167^{\prime} \\
16: 12 / 18: 59\end{array}$ & $\begin{array}{l}24 \\
19: 06 / 19: 30\end{array}$ & $\begin{array}{l}45^{\prime} \\
19: 30 / 20: 15\end{array}$ & $\begin{array}{l}2^{\prime} \\
20: 16 / 20: 18\end{array}$ & $\begin{array}{l}48^{\prime} \\
20: 18 / 21: 06\end{array}$ & $\begin{array}{l}98^{\prime} \\
21: 06 / 22: 44\end{array}$ & $\begin{array}{l}19^{\prime} \\
23: 07 / 23: 26\end{array}$ \\
\hline $\begin{array}{l}\text { Número } \\
\text { mensajes }\end{array}$ & 56 & 27 & 56 & 6 & 42 & 48 & 8 \\
\hline $\begin{array}{l}\text { Frecuencia } \\
\text { mensajes }\end{array}$ & $0,33 /$ minuto & $1,12 /$ minuto & $1,24 /$ minuto & $3 /$ minuto & $0,87 /$ minuto & $0,49 /$ minuto & $0,42 /$ minuto \\
\hline $\begin{array}{l}\text { Extensión } \\
\text { media }\end{array}$ & 2,17 líneas & 1,74 líneas & 1,98 líneas & 1,33 líneas & 1,71 líneas & 2,20 líneas & 1,37 líneas \\
\hline Firmados & 1 & 1 & 1 & 0 & 0 & $\begin{array}{l}10 \text { (3 de } \\
\text { redactores y } \\
7 \text { de } \\
\text { agencias })\end{array}$ & 0 \\
\hline
\end{tabular}

\footnotetext{
${ }^{7}$ El número de líneas de este texto no coincide con el original debido a la diferencia del ancho de las páginas y del cuerpo de letra.
} 


\begin{tabular}{|l|l|l|l|l|l|l|l|}
\hline Enlaces & 7 & 0 & 2 & 0 & 7 & 9 & 1 \\
\hline $\begin{array}{l}\text { Fotografías/ } \\
\text { Vídeos }\end{array}$ & 4 & 3 & 1 & 0 & 2 & 1 & 4 \\
\hline
\end{tabular}

La segunda tabla se ciñe al tamaño de los mensajes, su distribución a lo largo de la tarde y al porcentaje que representan.

Tabla 2. Evaluación de los mensajes por su tamaño

\begin{tabular}{|c|c|c|c|c|c|c|c|c|}
\hline MENSAJES & $1^{\text {a }}$ FASE & $2^{\mathrm{a}}$ FASE & $3^{a}$ FASE & $4^{a}$ FASE & $5^{\mathrm{a}}$ FASE & $6^{\mathrm{a}}$ FASE & $7^{a}$ FASE & TOTAL \\
\hline 1 LÍNEA & $\begin{array}{l}6 \\
(10,71 \%)\end{array}$ & $\begin{array}{l}7 \\
(25,92 \%)\end{array}$ & $\begin{array}{l}\mathbf{1 4} \\
(25 \%) \\
\end{array}$ & $\begin{array}{l}4 \\
(66,6 \%)\end{array}$ & $\begin{array}{l}\mathbf{1 6} \\
(38,1 \%)\end{array}$ & $3(6,2 \%)$ & $\begin{array}{l}\mathbf{1} \\
(12,5 \%)\end{array}$ & $\begin{array}{l}\mathbf{5 1} \\
(20,98 \%) \\
\end{array}$ \\
\hline $\begin{array}{l}\text { Hasta } 10 \\
\text { palabras }\end{array}$ & $3(5,3 \%)$ & $\begin{array}{r}4 \\
(14,8 \%) \\
\end{array}$ & $\begin{array}{r}8 \\
(14,3 \%) \\
\end{array}$ & $3(50 \%)$ & $\begin{array}{r}7 \\
(16,6 \%) \\
\end{array}$ & 0 & 0 & $\begin{array}{r}\mathbf{2 5} \\
(10,3 \%) \\
\end{array}$ \\
\hline $\begin{array}{l}\text { Más de } 10 \\
\text { palabras }\end{array}$ & $3(5,3 \%)$ & $\begin{array}{r}\mathbf{3} \\
(11,1 \%)\end{array}$ & $\begin{array}{r}\mathbf{6} \\
(10,7 \%)\end{array}$ & $\mathbf{1}(16,6 \%)$ & $\begin{array}{r}9 \\
(21,4 \%)\end{array}$ & $3(6,2 \%)$ & $\begin{array}{r}\mathbf{1} \\
(12,5 \%)\end{array}$ & $\begin{array}{r}\mathbf{2 6} \\
(10,7 \%)\end{array}$ \\
\hline 2 LÍNEAS & $\begin{array}{l}\mathbf{2 0} \\
(35,71 \%)\end{array}$ & $\begin{array}{l}\mathbf{1 4} \\
(51,85 \%)\end{array}$ & $\begin{array}{l}23 \\
(41,1 \%)\end{array}$ & $\begin{array}{l}\mathbf{2} \\
(33,3 \%)\end{array}$ & $\begin{array}{l}\mathbf{1 4} \\
(33,3 \%)\end{array}$ & $\begin{array}{l}\mathbf{2 0} \\
(41,6 \%)\end{array}$ & $\begin{array}{l}\mathbf{1} \\
(12,5 \%)\end{array}$ & $\begin{array}{l}94 \\
(38,68 \%)\end{array}$ \\
\hline 3 LÍNEAS & $\begin{array}{l}23 \\
(41,07 \%)\end{array}$ & $\begin{array}{l}\mathbf{3} \\
(11,11 \%)\end{array}$ & $\begin{array}{l}16 \\
(28,6 \%) \\
\end{array}$ & 0 & $8(19 \%)$ & $\begin{array}{l}19 \\
(39,6 \%) \\
\end{array}$ & $\begin{array}{l}\mathbf{1} \\
(12,5 \%)\end{array}$ & $\begin{array}{l}70 \\
(28,8 \%) \\
\end{array}$ \\
\hline $\begin{array}{l}\text { PIES (foto, } \\
\text { enlace, } \\
\text { etc.) }\end{array}$ & $\begin{array}{l}7 \\
(12,5 \%)\end{array}$ & $\begin{array}{l}\mathbf{3} \\
(11,11 \%)\end{array}$ & $\begin{array}{l}3 \\
(5,35 \%)\end{array}$ & 0 & $4(9,5 \%)$ & $\begin{array}{l}\mathbf{6} \\
(12,5 \%)\end{array}$ & $\begin{array}{l}\mathbf{5} \\
(62,5 \%)\end{array}$ & $\begin{array}{l}\mathbf{2 8} \\
(11,5 \%)\end{array}$ \\
\hline TOTAL & $\begin{array}{l}\mathbf{5 6} \\
(23,04 \%)\end{array}$ & $\begin{array}{l}\mathbf{2 7} \\
(11,11 \%)\end{array}$ & $\begin{array}{l}\mathbf{5 6} \\
(23,04 \%)\end{array}$ & $\begin{array}{l}6 \\
(2,47 \%)\end{array}$ & $\begin{array}{l}\mathbf{4 2} \\
(17,3 \%)\end{array}$ & $\begin{array}{l}\mathbf{4 8} \\
(19,75 \%)\end{array}$ & $8(3,3 \%)$ & $\begin{array}{l}\mathbf{2 4 3} \\
(100 \%)\end{array}$ \\
\hline
\end{tabular}

La última tabla recoge el número de errores tipográficos y repeticiones de mensajes detectados. Hay que destacar que sólo se han encontrado 14 errores tipográficos en un total de 243 mensajes $(5,7 \%)$, lo que demuestra bastante cuidado en la elaboración de los mensajes pese a la premura del relato.

Tabla 3. Errores tipográficos y repeticiones del mismo mensaje

En todo el relato

Errores Tipográficos 14

Repetición mismo mensaje 1

Aún así, es habitual encontrar problemas de calidad en las ediciones digitales, desde los errores de edición, gramaticales, sintácticos y de falta de concordancias hasta el riesgo de que se difundan informaciones incorrectas o erróneas por falta de tiempo para contrastar. Aunque para realizar un estudio sobre estos fallos, tal vez habría que esperar a que se consolidase la crónica de titulares u otros géneros similares.

El 19 de marzo de 2013, ElPaís.com volvió a utilizar el sistema de la "crónica de titulares" para narrar la Misa de Inicio de Pontificado del Papa Francisco. No se han incluido los datos para no hacer demasiado largo este trabajo. 


\section{CONCLUSIONES}

La Prensa escrita en el medio digital intenta competir con los audiovisuales en el relato instantáneo de un hecho noticioso "abierto e importante". Es una de las formas del "continuum" de la actualidad.

Tanto las ediciones digitales como los nuevos periódicos nacidos directamente en Internet no pueden limitarse a transmitir la imagen y el sonido en streaming, renunciando a la palabra escrita (su lenguaje propio), porque se convertirían en simples medios audiovisuales y perderían su personalidad.

Frente al lenguaje audiovisual que permite la instantaneidad, los medios escritos parecen haber comenzado a ensayar nuevos géneros periodísticos para relatar el hecho noticioso en el instante en que se produce.

Los titulares cortos permiten narrar la noticia en directo, pero surgen de forma aislada. A veces aparecen con una separación de pocos segundos, aunque carecen de hilo narrativo.

Este tipo de crónicas podría denominarse "crónica de titulares" o "crónica digital de titulares". Su composición se basa en las aportaciones realizadas por el lenguaje de Twitter, aunque los mensajes no se ciñen necesariamente a los 140 caracteres. Pueden ser consideradas una expresión profesional del "relato fragmentado".

Este nuevo género periodístico contiene también elementos hipertextuales con enlaces, y elementos audiovisuales y gráficos.

\section{BIBLIOGRAFÍA}

Bassets, Lluis (2013). El último que apague la luz. Sobre la extinción del periodismo. Madrid: Taurus.

Cerezo, J. M. (2008). Hacia un nuevo paradigma. La era de la información fragmentada: Revista TELOS 76. Consultado el 31 de octubre, 2013. Disponible en http://sociedadinformacion.fundacion.telefonica.com/telos/cuadernoimprimible.asp@id articulo $=6 \& \mathrm{rev}=76 . \mathrm{htm}$

Fernández, F. (2010). Making-Journal, una oportunidad para el periodismo en la Red. En J. Flores (dtor.), Reinventar el Periodismo y los Medios (p. 71-78). Madrid: Biblioteca de Ciencias de la Comunicación, Universidad Complutense.

Lozano Bartolozzi, Pedro (2006).El tsunami informativo. Panorama comunicativo del siglo XXI. Pamplona: EUNSA.

Martínez Arias, S. y De Ramón, Manuel (2013). Periodismo Ciudadano y Periodismo de Fuentes en las Redes Sociales. La Red Twitter como expresión del Relato Informativo Fragmentado. En M. Cebrián (IP), Cybermedia II: Desarrollos e Innovaciones del 
Periodismo en las Redes Sociales, en Internet y telefonía móvil. Convergencias, Modelos de Negocios, servicio y formación (REF. CSO2011-25235).

Moreno Espinosa, P. (2010). Contenidos especializados en Internet. En M. Quesada Montse (ed.), Internet como generadora de contenidos especializados. Barcelona: UPF, IECE, SLCS.

Salaverría, R. (2012). La edición periodística en la era del cierre continuo. Comunicando, UNIR blogs. Consultado el 5 de noviembre, 2013, Disponible en http://blogs.unir.net/comunicacion/2012/10/16/la-edicion-periodistica-en-la-era-delcierre-continuo/

\section{Manuel de Ramón}

Doctor en Ciencias de la Información por la Universidad Complutense, es profesor de Periodismo Especializado en la Facultad de Ciencias de la Información de la UCM e imparte clases en Masters y cursos de experto. Es Director del Curso de Comunicación Social de las Fuerzas Armadas. Anteriormente fue director del Departamento de Periodismo Especializado de la Universidad Europea de Madrid y profesor de la Universidad Nebrija. Ha sido redactor de Radio Nacional de España entre 1984 y 2007, redactor de TVE (1979-1984), Diario Ya (1978-1979) y corresponsal del Diario Avui (1988-1994). Colabora en la revista Atenea, donde ha sido Jefe del Área de Nacional (2008-2012). Como periodista ha viajado por Afganistán, Líbano, los Balcanes y otros países. 